\title{
APPLICATION OF CASSAVA PEELS ACTIVATED CARBON IN THE TREATMENT OF OIL REFINERY WASTEWATER - A COMPARATIVE ANALYSIS
}

\author{
Kigho Moses Oghenejoboh ${ }^{1 *}$, Smith Orode Otuagoma², Evuensiri Onogwharitefe Ohimor ${ }^{3}$
}

1 Department of Chemical Engineering, Delta State University, Oleh Campus, P.M.B. 22, Oleh, Nigeria

2 Department of Electrical/Electronic Engineering, Delta State University, Oleh Campus, P.M.B. 22, Oleh, Nigeria

3 Department of Chemical Engineering, College of Engineering, Federal University of Petroleum Resources, Mgbomro-Effurun, Nigeria

* Corresponding Author e-mail: kmoghene@yahoo.com

Received: 2016.01 .18 Accepted: 2016.03.04 Published: 2016.04.01

\begin{abstract}
A comparative analysis of the efficiency of activated carbon produced from fermented cassava peels (CPB), unfermented cassava peels (CPA) and commercial grade activated carbon $(\mathrm{CAC})$ in the treatment of refinery wastewater was carried out. $\mathrm{CPB}$ was found to be $8 \%$ and $18 \%$ more efficient when compared to CPA and CAC in the removal of COD, and $14 \%$ and $3 \%$ better than CAC and CPA respectively in the removal of $\mathrm{BOD}_{5}$. The removal efficiency of $\mathrm{Pb}^{2+}$ by $\mathrm{CPB}$ was $100 \%$ compared to $95 \%$ and $57 \%$ by CPA and CAC while $96 \%$ of phenol was removed by CPB against $93 \%$ and $83 \%$ by CPA and CAC respectively. This better performance of CPB over CPA and $\mathrm{CAC}$ is not unconnected with its higher $\mathrm{pH}$ resulting from the removal of cyanide from the peels during the fermentation process. However, despite the high phenol removal efficiency by $\mathrm{CPB}$, the concentration of phenol in the treated effluent does not meet the environmental guidelines for disposal. It is therefore, recommended that a two-stage $\mathrm{CPB}$ adsorption column arranged in series is necessary to treat refinery wastewater efficiently if it is desired to totally remove phenol from the effluent or reduce the concentration to $0.005 \mathrm{mg} / \mathrm{l}$ allowed by the Federal environmental protection agency (FEPA). The equilibrium adsorption test conducted showed that the Freundlich isotherm is a better fit for the adsorption of phenol by the three activated carbons with correlation coefficients $\left(\mathrm{R}^{2}\right)$ of $0.9364,0.9383$ and 0.9541 for CAC, CPA and $\mathrm{CPB}$ respectively. $\mathrm{CPB}$ was found to be a better adsorbent as it has the highest adsorptive capacity as evidenced from its better Freundlich exponent.
\end{abstract}

Keyword: Cassava peels, activated carbon, adsorption, refinery wastewater, environment, pollutant.

\section{INTRODUCTION}

Refinery wastewater most often contains hydrocarbons, spent catalyst and acid as well as soluble bases used as raw materials and treatment reagents. Most of these pollutants, which often include toxic, hazardous and priority pollutants, accounts for between $0.5-15 \%$ weight of the process wastewater [Bhatnaga and Minocha, 2009; Girish and Murty, 2013]. The need to comply with environmental regulations require that such pollutants be removed to an acceptable level before being discharged into the environment or recycled back into the plant depending on water economics [Nekoo and Shoreh, 2013; Hariz and Monser, 2014]. Since refinery wastewater pollutants is made up of both organic and inorganic sources, the treatment of such wastewater will involve chemical, physical, biological or a combination of these processes [Adeyinka and RimiRukeh, 1999; Fetter et al., 1982]. To measure the organic content of wastewater, the biological oxygen demand (BOD) and chemical oxygen demand (COD) as well as the total organic matter 
(TOC) lumped parameters are usually employed [El-Naas et al., 2010]. Various physical, chemical and biological methods are traditionally employed for the treatment of refinery wastewater which is normally oily in nature [Pant and Adholeya, 2007]. Some of these methods include gravity separator pretreatment, preceded by flocculation and dissolved air flotation (DAF) aimed at reducing the suspended solids, oil and grease in the wastewater before being subjected to further biological and or chemical treatment as required [Nekoo and Shohreh, 2013; Hussani et al., 2011]. Because the steps required for the traditional physicochemical treatment of industrial wastewater including refinery effluent is highly cost effective, adsorption on activated carbon is now widely used for the removal of a variety of organics and other pollutants from wastewater [Tandale andShide, 2008; Foo and Lee, 2010]. However, it was observed that the application of carbon in a form of commercial activated carbon or charcoal (ACC), which had proved to be very effective in treating most complex industrial wastewater, is exorbitantly expensive and about $10-15 \%$ of it is lost during regeneration [Tandale andShide, 2008]. There is a need therefore, to source for cheap alternative form of effective carbon-based adsorbents.

For decades now, research has been intensified to source for an inexpensive replacement for ACC from locally available materials, especially agricultural waste and by-products such as coconut shell and husk, rice husk, corn cob, banana peels, palm oil empty bunch, fly ash, cassava peels and many others [Ahmed and Tan, 2008; Alinnor and Nwachukwu, 2012; Chukwuedo and Okieimen, 2008; Rangaraj et al., 2002; Sarka and Acharya, 2006]. Recently, one agricultural waste that attracted serious attention of researchers, especially in sub-Saharan Africa, is cassava peels. This is because cassava peels currently constitute a disposal menace in most cassava processing countries where it serves as a staple food [Oghenejoboh, 2015; Oghenejoboh, 2012]. Earlier studies on the effectiveness of activated carbon produced from cassava peels in the treatment of wastewater generated from different industries was very encouraging. For example, it was found to remove more than $85 \%$ phenol from water artificially contaminated with phenol [Alinnor and Nwachukwu, 2012]. In another study, cassava peels activated carbon was reported to adsorb $80 \%$ of $\mathrm{Pb}^{2+}$ and $77 \%$ $\mathrm{Cu}^{2+}$ from water collected from a stagnant pond where various waste is indiscriminately dumped by villagers [Ilaboya et al., 2013].

However, in all these documented studies, little or no attention is paid to the cyanide content of the cassava peels. Cyanogen glycoside found in great quantity in cassava is concentrated majorly in the peels [Oghenejoboh, 2015]. Though, cyanogenic glycoside may not be toxic and harmful as a compound but it hydrolyses to form toxic and harmful hydrocyanic acid [Olayinka, 2013; Oti, 2002]. This may possibly happen when the cassava peels activated carbon is contacted with the wastewater during the adsorption process. Despite the unstable nature of cyanogenic glycoside, it can be converted to heat resistant salts that may persist in the effluent water if it is not subjected to further treatment stage such as alkaline chlorination which involves conversion of the cyanide to cyanogen chloride that can easily be hydrolyzed to harmless cyanate at alkaline $\mathrm{pH}$ [Eisler and Wiemeyer, 2004]

In the present study, the adsorption parameters, efficiency and adsorption isotherms for commercial grade activated carbon is compared with activated carbon produced from cyanide laden and cyanide free cassava peels in the treatment of refinery wastewater

\section{MATERIALS AND METHODS}

Some of the materials used for the experiments were fresh peelings of bitter cassava (utilissima) variety obtained from a cassava farm in Ughelli, Delta State of Nigeria, wastewater collected from the downstream of the dry air flotation (DAF) unit of the wastewater treatment plant of the Warri refinery and petrochemical company (WRPC) in Warri, Delta state of Nigeria, commercial grade activated carbon (CAC) obtained from Pyrex chemical/laboratory equipment in Benin city, citric acid, distilled water, muffle furnace, crucibles, measuring cylinders, filter papers, beakers, weighing balance, mortar and pestle as well as Perkin Elmer HGA 900 spectrophotometer.

\section{Production of cassava peels activated carbon}

The fresh cassava peels were divided into two parts labeled CPA and CPB. CPA was properly washed in distilled water without other pretreatment; sun-dried for 7 days under scorching sun and packaged in an air-tight polythene bag in preparation for the experiment. CPB was soaked 
in an open container exposed to the atmosphere for 5 days with the water being replaced with fresh one every 24 hours to release cyanogen glycoside contained in the peels before carbonation. After the 5 day fermentation process, the fermented cassava peels were properly washed three times with distilled water before drying it under scorching sun for 7 days.

The dried CPA and CPB were then subjected to size reduction by crushing using a mortar and pestle and then filtered with a $500 \mu \mathrm{m}$ sieve filter. The filtrates were then washed thoroughly with distilled water to remove any unwanted matter introduced during the crushing process. The washed CPA and CPB samples were then placed in an oven maintained at $105{ }^{\circ} \mathrm{C}$ for 12 hours for moisture removal. $500 \mathrm{~g}$ each of the dried CPA and CPB were measured and introduced into the hot zone of the muffle furnace for 120 minutes at $380{ }^{\circ} \mathrm{C}$. The carbon formed was allowed to cool for 5 hour at room temperature. $100 \mathrm{~g}$ each of the carbonized and cooled CPA and CPB were then activated with $150 \mathrm{~g}$ 1.0 M Zinc chloride following the method employed by [Awoyale et al., 2012].

\section{Adsorption test and analysis}

Three fixed, equal size adsorption columns packed with commercial grade activated carbon (CAC), unfermented cassava peels activated carbon (CPA) and fermented cassava peels activated carbon $(\mathrm{CPB})$ were arranged in parallel as shown in Figure 1. Oil and suspended particlefree wastewater obtained from the outlet of the DAF unit of the WRPC wastewater treatment plant was placed in a 20 litres plastic container with its outlet connected to the three columns by means of valves that were opened to allow equal volume of wastewater through the three adsorption columns by gravity. In order to provide a high interfacial area for adsorption, distilled water was passed through the columns to wet the activated carbon bed before the experiment. Effluents collected from flasks 1-3 were analysed at three hour's interval for 9 hours to obtain triplicate reading of the adsorption parameters for comparative purpose.

The refinery wastewater as well as the treated effluent obtained from flasks 1-3 were analysed for $\mathrm{COD}, \mathrm{BOD}_{5}$, TDS, turbidity, $\mathrm{pH}, \mathrm{DO}$ and heavy metals. The COD, $\mathrm{BOD}_{5}$, TDS, $\mathrm{pH}$, $\mathrm{DO}$, conductivity and turbidity were analysed by means of the respective meters while heavy metal analysis was done using UV absorption spectrophotometer.

\section{Batch adsorption model study}

Batch adsorption experiments were carried out to compare the efficiency of adsorption of phenol, a prominent pollutant in oil refinery wastewater by the three activated carbon used in this work. Completely mixed batch reactors (CMBR) consisting of $20 \mathrm{ml}$ glass centrifuge tubes containing $5 \mathrm{gm}$ each of the activated carbon to be tested and $15 \mathrm{ml}$ of the refinery wastewater, closed with open closure and sealed with Teflon-lined silicone septa were used for the experiment. Three replicates CMBR were used for each phenol concentrations of $20,40,60,80$ and $100 \mathrm{mg} / 1$ prepared from the initial stock of $120 \mathrm{mg} / \mathrm{l}$ of phenol in the analysed refinery wastewater. The tube's contents were agitated with vortex mixer and allowed to attain to equilibrium at room temperature for 12

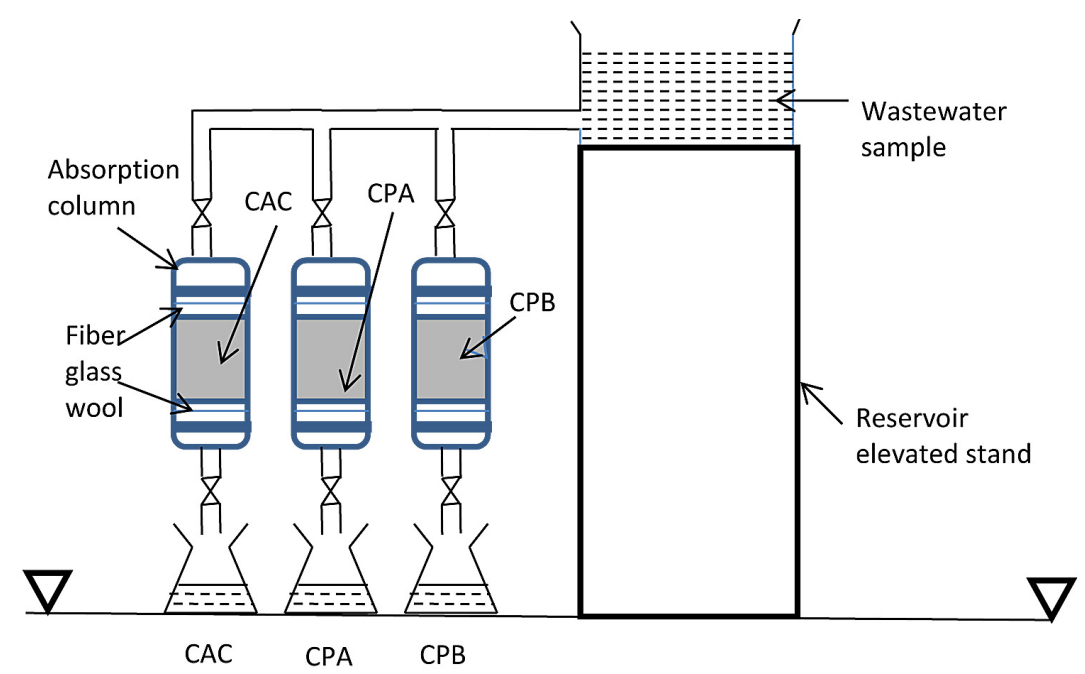

Figure 1. Experimental set-up for fixed-bed activated carbon treatment of refinery wastewater 
hours. After the 12 hours equilibration period, the tubes were then centrifuged at $2500 \mathrm{rpm}$ for 30 minutes to separate the solid and liquid phase. A $100 \mu \mathrm{L}$ aliquot was removed from each tube and transferred to $5 \mathrm{ml}$ vial and analysed by means of a UV spectrophotometer to measure the absorbance from where the equilibrium concentration was obtained by means of a calibration chart. The concentration of phenol $\left(\mathrm{C}_{\mathrm{S}}\right)$ adsorbed by each of the tested activated carbon was then calculated as follows [Oghenejobh et al., 2008]:

$$
C_{S}=\frac{V}{M}\left(C_{o}-C_{e}\right)
$$

where: $C_{S}$ - is the concentration of phenol adsorbed by the activated carbon $(\mathrm{mg} / \mathrm{g})$, $C_{o}$ - is the initial concentration of phenol in the wastewater $(\mathrm{mg} / \mathrm{l})$,

$V-$ is the volume of wastwater used $\left(\mathrm{cm}^{3}\right)$, $M$ - is the mass of activated carbon used (g).

The Langmuir and Freundlich isotherm models were used to test the adsorption efficiency of the three activated carbon studied in treating phenol-laden refinery wastewater. The model equations are:

- Freundlich:

$$
\log C_{S}=\log K_{f}+\frac{1}{n} \log C_{e}
$$

- Langmuir:

$$
\frac{C_{S}}{C_{e}}=\frac{1}{\alpha \beta}+\frac{C_{e}}{\beta}
$$

Where $K_{f}, n, \alpha$ and $\beta$ are the partition coefficient, Freundlich exponent, Langmuir constant and soption capacity respectively.

\section{RESULTS AND DISCUSSION}

The results of the wastewater anlaysis, before and after treatment with the three tested activated carbons, is presented in Table 1, while Figure 1 and Table 2 show the phenol adsorption capacity of the three activated carbons and their respective Freundlich and Langmuir model parameters

It will be observed from Table 1 that the $\mathrm{pH}$ of the refinery effluent water increased slightly from 6.07 to $6.62,6.69$ and 7.52 after treatment with commercial grade activated carbon (CAC) and unfermented cassava peels activated carbon (CPA) and fermented cassava peels activated carbon (CPB) respectively. The gradual transition of the treated effluent from acidic to basic may be as a result of the $\mathrm{H}^{+}$concentration of the adsorbent. CPB with very low concentration of cyanide, resulting from the fermentation process exhibits the highest $\mathrm{pH}$ of 7.52 , which is highly favorable for adsorption of organic and trace metal pollutants from wastewater [Alinnor and Nwachukwu, 2012; Awoyale et al., 2012]. The results of this study as can be seen from Table 1 , agrees with the observation that the higher the $\mathrm{pH}$ of an adsorbent, the higher the removal efficiency of heavy metals and organic materials by the adsorbent from wastewater. As noted by Low et al. [Low et al., 1995], the surface of the adsorbent functional group is usually repulsively associated with hydroxonium ions $\left(\mathrm{H}_{3} \mathrm{O}^{-}\right)$at low $\mathrm{pH}$ which invariably reduce the removal efficiency of heavy metals and organics during adsorption. From the analysis results presented in Table 1, it could be observed that the heavy metals removal efficiency from the wastewater increased as the $\mathrm{pH}$

Table 1. Analyses result of untreated and treated Refinery wastewater

\begin{tabular}{|l|c|c|c|c|}
\hline \multirow{2}{*}{ Parameters } & \multirow{2}{*}{ Before treatment } & \multicolumn{3}{|c|}{ After treatment } \\
\cline { 3 - 5 } & & CAC & CPA & CPB \\
\hline $\mathrm{pH}$ & 6.07 & 6.62 & 6.69 & 7.52 \\
\hline $\mathrm{COD}(\mathrm{mg} / \mathrm{l})$ & 384 & 172 & 136 & 102 \\
\hline $\mathrm{BOD}_{5}(\mathrm{mg} / \mathrm{l})$ & 52.5 & 14.8 & 8.9 & 7.5 \\
\hline $\mathrm{DO}(\mathrm{mg} / \mathrm{l})$ & 4.2 & 12.8 & 20.2 & 22.1 \\
\hline Electrical conductivity $(\mu \mathrm{S} / \mathrm{cm})$ & 1520 & 1522 & 1520 & 1520 \\
\hline TDS $(\mathrm{mg} / \mathrm{l})$ & 220 & 218 & 217 & 217 \\
\hline Turbidity $(\mathrm{NTU})$ & 52 & 2 & 0 & 0 \\
\hline $\mathrm{Pb}^{2+}$ & 2.05 & 0.89 & 0.10 & $<0.001$ \\
\hline $\mathrm{Cu}^{2+}$ & 4.40 & 1.05 & 0.88 & 0.26 \\
\hline Fe $^{3+}$ & 8.49 & 3.72 & 2.58 & 2.19 \\
\hline Phenol $(\mathrm{mg} / \mathrm{l})^{*}$ & 120 & 20 & 8 & 5 \\
\hline
\end{tabular}

Comments: CAC - commercial grade activated carbon; CPA - unfermented cassava peels activated carbon; $\mathrm{CPB}$ - fermented cassava peels activated carbon. 
Table 2. Freundlich and Langmuir parameters for CAC, CPA and CPB

\begin{tabular}{|c|c|c|c|c|c|c|}
\hline \multirow{2}{*}{ Activated carbon } & \multicolumn{3}{|c|}{ Freundlich Isotherm } & \multicolumn{3}{c|}{ Langmuir Isotherm } \\
\cline { 2 - 7 } & $\mathrm{n}$ & $\mathrm{k}$ & $\mathrm{r}^{2}$ & $\alpha$ & $\beta$ & $\mathrm{r}^{2}$ \\
\hline CAC & 0.9842 & 0.5915 & 0.9364 & 0.0078 & 243.91 & 0.1097 \\
\hline CPA & 1.0549 & 0.4053 & 0.9383 & 0.0501 & 95.24 & 0.7231 \\
\hline CPB & 1.0893 & 0.4146 & 0.9541 & 0.0033 & 909.09 & 0.0142 \\
\hline
\end{tabular}

increases. Performance efficiencies of CPB, CPA and $\mathrm{CAC}$ were: $100 \%, 95 \%$ and $57 \%$ for lead and $96 \%, 93 \%$ and $83 \%$ for phenol respectively. Figure 2 shows the phenol removal efficiency by the three activated carbons. Though, CPB recorded $96 \%$ efficiency in the removal of phenol from the wastewater, the final concentration of phenol in the treated effluent is still above $0.005 \mathrm{mg} / \mathrm{l}$ allowed for the industry [FEPA, 1991]. The initial concentration of phenol in the treated wastewater stock is highly responsible for this trend, since it determines the equilibrium contact time for the adsorption process. The lower the initial phenol concentration in the wastewater stock, the shorter the equilibrium time, hence the better the adsorption efficiency [Alinnor and Nwachukwu, 2012]. Research showed that coconut shell activated carbon has the capacity to adsorb $205.8 \mathrm{mg} / \mathrm{g}$ of phenol from wastewater, which makes it a better adsorbent if phenol is the only targeted pollutant [Girish and Murty, 2013], however, coconut shells are not readily abundant like cassava peels. If it is desired, therefore, to properly treat refinery wastewater with cassava peels activated carbon, a two-stage fermented cassava peels activated carbon adsorption column arranged in series will be necessary. Thus, any trace metals and other pollutants, including phenol, which were not removed during the first stage adsorption column

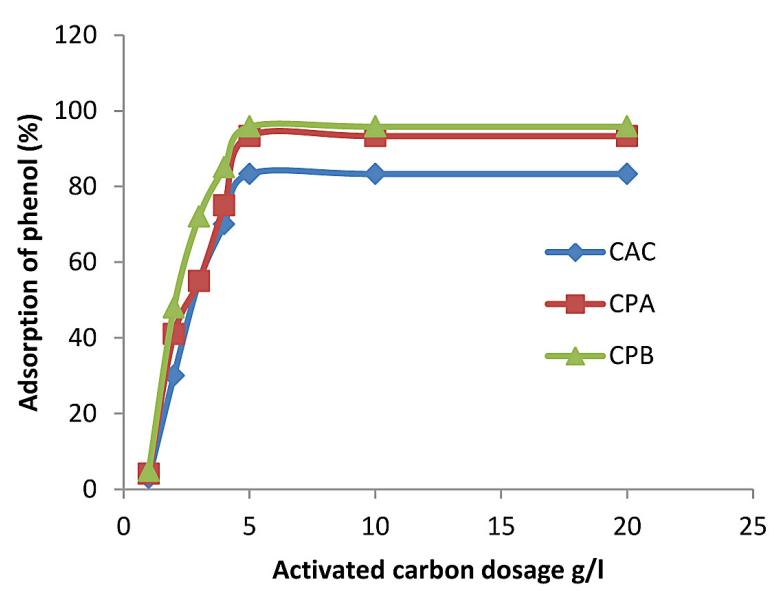

Figure 2. Comparative adsorption capacity of phenol present in refinery wastewater by CAC, CPA and CPB will be totally removed in the second stage adsorption column

In addition to the high removal efficiency of heavy metals and some organics by cassava peels activated carbon, especially CPB, other lumped organic parameters such as $\mathrm{COD}$ and $\mathrm{BOD}_{5}$ as well as turbidity were also drastically reduced. The COD level reduced by 55\%, 65\% and $73 \%$ respectively with $\mathrm{CAC}, \mathrm{CPA}$ and $\mathrm{CPB}$, while the $\mathrm{BOD}_{5}$ reduced by $72 \%, 83 \%$ and $86 \%$ respectively. The turbidity, on other hand, was reduced from 52 NTU to zero within the 5 hours treatment period. TDS and electrical conductivity of the analysed wastewater remained relatively constant after treatment with the three activated carbons. This is in order and agrees with the findings of Ilaboya et al. [2013] who noted that adsorption does not remove TDS from wastewater. The electrical conductivity which is a measure of the ability of the discharged water to carry electrical current, is a function of the concentration and mobility of ionic species in the water. This is determined by the concentration of total dissolved solids (TDS) in the water. The higher the TDS contained in a water sample the higher the conductivity of the water. The relative stability of the conductivity of the treated wastewater is unrelated with the stability observed for the TDS as contained in Table 1.

The equilibrium adsorption data were modeled using a two-parameter isotherm models-the Freundlich and Langmuir isotherms. As can be seen from Figure 2, the Freundlich model correlates well with the three activated carbons used in the study, as evidenced by the high correlation coefficient $\left(\mathrm{R}^{2}\right)$. The Langmuir model does not fit the equilibrium data at all. The magnitude of the Freundlich exponent (n) which describes the adsorptive capacity of an adsorbent as seen from Table 2 is higher for CPB followed by CPA and least for CAC. This is an indication that CPB is a better adsorbent than the remaining two activated carbons. It was noted that an adsorbent having a Freundlich exponent greater than 1 is highly favored for adsorption [Saed et al., 2005]. 


\section{CONCLUSIONS}

It was established from the results of this study that activated carbon produced from agricultural waste such as cassava peels hold a great promise in the treatment of wastewater containing organic materials and trace heavy metals. Fermented cassava peels activated carbon had the highest removal efficiency for all the refinery wastewater pollutants followed by un-fermented cassava peels activated carbon. This shows that the presence of free cyanide contained in the cassava peels lowers its $\mathrm{pH}$ which invariably impedes the efficiency. The adsorption of pollutants to cassava peels activated carbon is best described by the Freundlich isotherm with fermented cassava peels activated carbon exhibiting the highest adsorptive capacity. Therefore, for the efficient treatment of industrial wastewater containing organic and metallic pollutants fermented cassava peels activated carbon is preferred to unfermented cassava peels activated carbons.

\section{REFERENCES}

1. Adeyinka J.S. and Rim-Rukeh A., 1999. Effect of hydrogen peroxide on industrial waste water effluent: A case study of Warri Refining and Petrochemical Company. Environs. Mont. Assess. 59, 249-256.

2. Alinnor I.J. and Nwachukwu M.A. 2012. Adsorption of phenol on surface-modified cassava peel from its aqueous solution. International Journal of Environmental Science, Management and Engineering 1(2), 68-74.

3. Awoyale A.A, Eloka-Eboka A.C. and Odubiyi A.O. 2012. Production and experimental efficiency of activated carbon from local waste bamboo for wastewater treatment. International Journal of Engineering and Applied Sciences 3(2), 8-10.

4. Bhatnagar A. and Minocha A.K. 2009.Adsorptive removal of 2, 4-dichlorophenol from water utilizing Punica granatum peel waste and stabilization with cement. J. Hazard. Mat. 168, 1111-1113.

5. Chukwuedo M.E. and Okieimen F.E. 2008. Enhanced metal adsorption by groundnut husks modified with citric acid, J. Chem. Soc. Nigeria, 33(2), $.50-51$.

6. Eisler R. and Wiemeyer S.N. 2004. Cyanide hazards to plants and animals from gold mining and related water issues. Rev. Environ. Contam. Toxicol., 183, 24-25.

7. El-Naas M.H, Al-Zuhair S and Alhaji M. 2010. Reduction of COD in refinery wastewater through adsorption on date-pit activated carbon. J. Hazard. Mater. 173 (1-3), 750

8. FEPA, 1991. Environmental guidelines and standards for the petroleum industry in Nigeria. A publication of the Federal Environmental Protection Agency, Lagos-Nigeria.

9. Fetter W.Jr., Scoey W.E. and Spangler F.L. 1982. Alum clarification of cations in refinery wastewater. Journal of Water Control Fed. 49, 742.

10. Foo P.Y.I. and Lee L.Y. 2010. Preparation of activated carbon from parkia speciosa pod by chemical activation. In: Proceedings of World Congress on Engineering and Computer Science (WCEC 2010), San Francisco, U.S.A., vol. II, 98-99.

11. Girish C.R. and Murty V.R. 2013. Adsorption of phenol from wastewater using locally available adsorbents. Journal of Environmental Research and development, 6(3A), 763-769.

12. Hammed B.H. and Tan I.A.W. 2008. Adsorption isotherm, kinetic modeling and mechanism of 2, 4, 6-trichlorophenol on coconut husk-based activated carbon. Chem. Eng. J. 144, 235-237.

13. Hariz I.B. and Monser L. 2014. Sulfide removal from petroleum refinery wastewater by adsorption on chemically modified activated carbon. International Water Technology Journal, 4(4), 264-267.

14. Hussani A.H., Salehi S.B., Borghei M. and Siavashani B. 2011. Organic removal efficiency of the nanofiltration and adsorption hybrid system in high strength wastewater. Water and Waste 22(1), 42.

15. Ilaboya I.R., Oti E.O., Ekoh G.O. and Umukoro L.O. 2013. Performance of activated carbon from cassava peels for the treatment of effluent wastewater. Iranica Journal of Energy and Environment 4(4), 361-370.

16. Low K.S., Lee C.K. and Loo A.C. 1995. Removal of metals from electroplating wastes, using banana pith. Bioresour. Technol., 51, 227-229.

17. Nekoo S.H. and Shohreh F. 2013. Experimental study and adsorption modeling of COD reduction by activated carbon for wastewater treatment of oil refinery. Iran J. Chem. Chem. Eng., 32(3), 81-83.

18. Oghenejoboh K.M., Abowei M.F.N. and Puyate Y.T. 2008. Sorption mechanism of Nigerian crude petroleum into soil medium. Pollution Research 27(1), 7-8.

19. Oghenejoboh K.M. 2012. Effects of starch fermentation on the shelf-life of cassava starch based adhesive. British Biotechnology Journal 2(4), 257-259.

20. Oghenejoboh K.M. 2015. Effects of cassava wastewater on the quality of receiving water body intended for fish farming. British Journal of Applied Science and Technology 6(2), 164-165.

21. Olayinka A.S. 2013. Assessment of toxic potentials of cassava effluent on Clarias Ganepinus, International Journal of Agricultural Science and Research 3(3), 157.

22. Oti E.E. 2002. Acute toxicity of cassava mill effluent to the African Catfish Fingerlings. Journal of 
Aquatic Science 17(1), 31.

23. Pant D. and Adholeya A. 2007. Biological approaches for treatment of distillery wastewater: A review, Bioresour. Technol. 98(12), 2321.

24. Rengaraj S., Moon S.H., Sivabalan R., Aranbindoo R. and Murugesan V. 2002. Agricultural soil waste for the removal of phenol from water and wastewater by palm seed coat activated carbon. J. Waste Management 22, 543-545.

25. Saed K., Johari M., Noor M.M. and Yusuf B. 2005. Sugarcane bagasse as an adsorbent for dye remov- al. Journal of Industrial Pollution Control 21(1), 3.

26. Sarka M. and Acharya K.P. 2006. Use of fly ash for the removal of phenol and its analogues from contaminated water. Waste Manage. 26, 559-561.

27. Tandale J.P. and Shide N.H. 2008. Preparation of low cost adsorbent and its characterization. Poll. Res. 27(4), 635.

28. Ton M.A., Purcell P.J. and Zhao Y. 2012. Oil refinery wastewater treatment using physicochemical. Fenton and photo-Fenton oxidation processes, J. Environ. Sci. Health 47(3), 435. 